\title{
CONCEPÇÕES DE ALUNOS INGRESSANTES DO ENSINO MÉDIO SOBRE 0 CONCEITO DE DIVISÃO CELULAR
}

\author{
Ingrid Andrade Reis ${ }^{1}$, Gustavo Luiz de Sousa Bezerra ${ }^{2}$, \\ Isabel de Conte Carvalho de Alencar ${ }^{3}$, Manuella Villar Amado4 \\ Instituto Federal do Espírito Santo - Campus Santa Teresa \\ Rodovia ES-080, km 93, São João de Petrópolis, Santa Teresa - ES, 29660-000
}

\begin{abstract}
RESUMO
O presente trabalho teve como objetivo avaliar as concepções prévias sobre o conteúdo de divisão celular dos alunos ingressantes no ensino médio integrado a cursos técnicos do Ifes Campus Vitória. Para isso, os estudantes responderam a questões objetivas, que permitiu a caracterização do perfil dos mesmos, e a uma questão aberta sobre o conceito de divisão celular, que possibilitou uma análise de suas concepções sobre o conteúdo de maneira qualitativa. Um total de 139 alunos foram entrevistados. Os resultados mostraram que o conhecimento sobre o assunto divisão celular é bastante restrito ao ambiente formal de ensino e que os alunos possuem apenas uma visão limitada e generalizante do tema. Em vista dos resultados indicaram que o ensino dos conceitos de divisão celular seja precedido de um momento de problematização que apresente aos alunos fatos e situações encontradas no cotidiano e na mídia que estejam vinculadas ao tema, a fim de possibilitar uma aprendizagem significativa e auxiliar na formação de cidadãos autônomos, éticos, participativos e responsáveis.
\end{abstract}

Palavras-chave: ensino de genética, divisão celular, concepções prévias.

\begin{abstract}
This study aimed to evaluate the preconceptions about the content of cell division of students entering the integrated technical courses IFES Campus Vitoria high school. For this, students answered objective questions, which allowed the characterization of the profile of the same, and an open question about the concept of cell division, which allowed for an examination of his views on the content of qualitative way. A total of 139 students were interviewed. The results showed that knowledge on the subject cell division is quite restricted to formal learning environment and students have only a limited view of the subject and generalizing. In view of the results indicated that teaching the concepts of cell division is preceded by a moment of questioning students to present facts and situations encountered in daily life and in the media who are involved in the issue in order to enable meaningful learning and assist in training autonomous, ethical, participatory and responsible citizens.
\end{abstract}

Keywords: teaching genetics, cell division, previous conceptions.

\footnotetext{
${ }^{1}$ Iniciação científica FAPES/Instituto Federal do Espírito Santo, campus Vitória/ingrid.andrade-r@hotmail.com

2 Iniciação científica FAPES/Instituto Federal do Espírito Santo, campus Vitória/gus.l@hotmail.com

${ }^{3}$ Mestre em Biologia Animal/ Instituto Federal do Espírito Santo, campus Santa Teresa/ idccalencar@gmail.com

${ }^{4}$ Doutora em biotecnologia/ Programa de Pós-graduação em educação em ciência e matemática, Instituto Federal do Espírito Santo, campus Vila Velha/ manuellaamado@gmail.com
} 


\section{INTRODUÇÃo}

O enfoque dado nas aulas de biologia parece perpetuar uma constante, onde somente o conhecimento científico tem valor e coerência, reservando ao aluno um papel passivo, como apresentado por Chalmers (1993). Este fato é preocupante, podendo levar o estudante a encontrar dificuldade em relacionar os conhecimentos disponibilizados em sala de aula com os fatos de seu cotidiano (FRACALANZA \& NETO, 2003). Hoje em dia se admite que as ideias prévias dos estudantes estejam presentes em todas as situações de aprendizagem em sala de aula (DRIVER, 1988), podendo ser utilizada como mais um recurso didático para um ensino contextualizado. As ideias prévias ou concepções prévias são os conhecimentos ou as representações construídas pelos indivíduos de uma sociedade. São os conhecimentos derivados da primeira leitura de mundo por parte dos indivíduos, e da necessidade que os indivíduos têm de responder e resolver os problemas do cotidiano (FLORENTINO, 2004). Esse conhecimento é passado de geração em geração, é superficial e não sistemático o que não significa dizer que seja um falso conhecimento.

Nos dias atuais, o ensino da divisão celular nas instituições de ensino médio em nosso país (de grande importância tanto para fatores sociais como para o aprendizado) vem enfrentando dificuldades, tornando sua abordagem menos concreta e efetiva. Embora sejam bem variados entre os alunos, os conceitos de aprendizagem significativa e sua concepção também influenciam no aprendizado dos processos em questão. Segundo Ausubel (1982), a aprendizagem significativa cognitiva, ou seja, aquela a qual resulta do armazenamento organizado na mente do ser que aprende, ocorre principalmente através de duas condições: a disposição do aluno para aprender e o material didático desenvolvido, que deve ser, sobretudo, significativo para o aluno.

Esta maneira é a ideal para a verdadeira compreensão de conceitos, o que implica na aquisição de significados claros. Para a avaliação da aprendizagem significativa, o método prático consiste em buscar soluções de problemas diversos através de testes de compreensão, utilizando-se de recursos diferentes daqueles utilizados anteriormente no material instrucional (AUSUBEL, 1982). 
As pesquisas em educação têm se preocupado com a análise das concepções alternativas dos alunos, uma vez que a aprendizagem escolar é influenciada pelo que o aluno já sabe, e principalmente, pelo fato das concepções alternativas não coincidirem com o cientificamente aceito (SIMPSON; ARNOLD, 1982). O conhecimento das concepções alternativas dos alunos é fato de grande importância para o planejamento das atividades pedagógicas, uma vez que as ideias dos estudantes sobre as estruturas biológicas muitas vezes não coincidem com o contexto cientificamente aceito (BASTOS, 1991). Para que se possa constatar, de fato, se o aluno desenvolveu ou não as habilidades necessárias à aquisição da aprendizagem significativa em relação à divisão celular, foi aplicado um questionário aos alunos de turmas ingressantes do ensino médio no Ifes, campus Vitória.

\section{PROCEDIMENTOS METODOLÓGICOS}

\section{Local e Sujeitos}

O local da pesquisa foi o Instituto Federal do Espírito Santo campus Vitória localizado na Av. Vitória, 1729, bairro Jucutuquara. Os sujeitos foram alunos ingressantes nos cursos técnicos de Mecânica, Eletrotécnica, Estradas e Edificações integrados ao Ensino Médio.

\section{Percepção Prévia dos Sujeitos}

A percepção prévia dos sujeitos foi obtida a partir de um questionário com questões abertas e fechadas e seguiu uma abordagem qualitativa. As questões fechadas visaram a caracterização dos alunos, através do registro de informações como sexo, idade, matérias de preferência, conteúdos vistos no ensino fundamental, participação em aulas práticas e contato com o assunto da pesquisa. Além disso, foram recolhidas diversas acepções já adquiridas pelos alunos por meio de uma questão aberta sobre o assunto de divisão celular. A pergunta foi: “0 que você entende por divisão celular?".

As respostas obtidas foram classificadas e categorizadas em: Conceituação correta; Conceituação Generalizante; Conceituação Parcialmente correta e Conceituação incorreta. Respostas em branco também foram consideradas para análise. (Tabela 1). As respostas respondidas corretamente, parcialmente corretas e incorretamente foram subdivididas em 
grupos específicos para uma melhor análise dos resultados. A análise das resoluções foi obtida através de uma catalogação, conforme a definição das palavras e as proximidades entre o significado das mesmas (BOGDAN; BIKLEN, 1991; ALVES-MAZZOTTI; GEWANDSZNAJDER, 1999). Foram usadas técnicas de indução analítica, mediante leitura sucessiva das respostas (ARDOINO, 1998).

Tabela 1. Categorias gerais referentes à respostas dos alunos sobre conhecimentos prévios relacionados a divisão celular.

\begin{tabular}{|l|l|}
\hline Conceituação Correta (CC) & \begin{tabular}{l} 
Quando o aluno responde de maneira correta. \\
\hline Conceituação Generalizante (CG)
\end{tabular} \\
$\begin{array}{l}\text { Quando o aluno responde de forma vaga, se } \\
\text { referindo ao processo de forma óbvia. }\end{array}$ \\
\hline (CPC) & $\begin{array}{l}\text { Quando o aluno responde corretamente, mas de } \\
\text { forma breve, se reportando a conhecimentos } \\
\text { parciais do assunto em questão. }\end{array}$ \\
\hline Conceituação Incorreta (CI) & $\begin{array}{l}\text { Quando não há relação da resposta do aluno com } \\
\text { os critérios estabelecidos como resposta correta. }\end{array}$ \\
\hline Não respondeu (NR) & $\begin{array}{l}\text { Quando o aluno deixou o espaço para resposta em } \\
\text { branco. }\end{array}$ \\
\hline
\end{tabular}

\section{RESULTADOS E DISCUSSÃO}

Por meio do teste aplicado, foi possível ter uma noção de como os alunos da série investigada organizam suas ideias sobre a divisão celular. É importante ressaltar que os dados foram categorizados de modo em que os resultados fossem, ao mesmo tempo, coletados e organizados representando as quatro turmas pesquisadas ao mesmo tempo, para uma melhor análise das turmas ingressantes como um todo.

\section{Questionário de caracterização}

De modo geral, foram poucos os obstáculos encontrados para a aplicação desta primeira parte do questionário.

A maior parte dos alunos é pertencente ao sexo masculino (65\%), o que é um fator comum em todos os cursos técnicos Integrados ao Ensino Médio do Ifes campus Vitória. A 
segunda questão, que tratava da faixa etária dos alunos, também representa uma visão geral dos estudantes do Ensino Médio. Os alunos, em sua maioria, possuem 15 anos (59\%), o que é bem comum para a primeira série do Ensino Médio. Uma porcentagem menor que a de 15, mas maior que a de 14 anos (18\%), foi a de alunos com 16 anos (22\%). Isso se deve ao fato de alguns alunos já terem cursado o primeiro ano do Ensino Médio em outra instituição, que é um dado que interfere de forma significativa nos resultados.

Na Figura 1a, é retratada a relação dos alunos com o conteúdo de divisão celular, ou seja, se já tiveram contato com a mesma antes do seu ingresso no Ifes. Como se pode perceber, uma grande parcela dos alunos relataram já possírem um contato prévio com o assunto.

Para uma melhor análise do contato prévio com a meiose e a mitose, a quarta questão (Figura 1b) buscou retratar de que modo esse contato foi adquirido: grande parte dos alunos teve como forma de aquisição de conhecimento do assunto a escola em si (87\%). Outro meio de contato significante foi o livro didático (50\%). Geralmente, os livros acompanham os alunos em seus estudos no Ensino Fundamental (ou na primeira série do Ensino Médio), o que provavelmente levou vários alunos a assinalarem as duas opções citadas. Podemos observar que os principais meios de contatos com o conteúdo de divisão celular estão vinculados em ambiente de ensino formal.

FIGURA 1. Representação gráfica percentual das respostas obtidas para as questões referentes ao contato prévio com a divisão celular e os meios de contato adquiridos.

a)

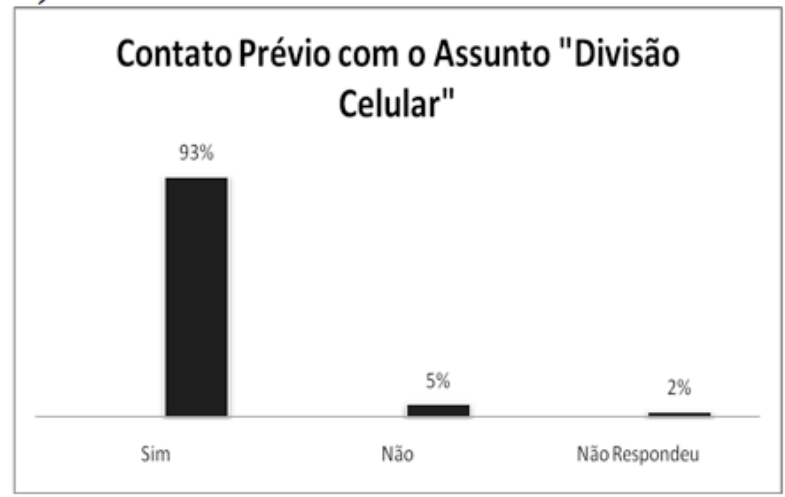

b)

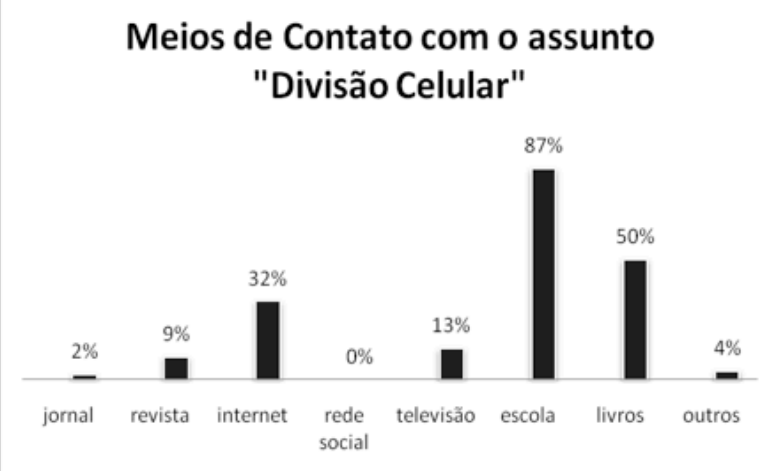

Fonte: Dados da pesquisa. 
Outros meios que possuem maior influência nessa aquisição, foram, também, a internet (32\%), televisão (13\%) e revistas (9\%). Como poucos alunos deixaram de responder esta questão, os que não tiveram contato prévio no colégio provavelmente teriam visto algo relacionado à divisão celular em reportagens, notícias ou por artigos na internet. Os dados de caracterização também mostraram que $81 \%$ dos alunos estudaram em instituições particulares particulares antes de entrarem no Ifes. Isto sugere que a maioria dos alunos provém de uma classe social relativamente alta em relação aos que vieram de colégios municipais (17\%) ou estaduais (3\%). Uma porcentagem expressiva de alunos (90\%) fizeram curso pré-Ifes. Embora a exploração do conteúdo seja menos aprofundado que nas escolas, o curso contribui para um melhor desenvolvimento não só da matéria de Biologia, mas sim de todas que são cobradas no processo seletivo. Uma pequena parcela (9\%) dos alunos não fizeram o curso preparatório, e 1\% não responderam.

Em uma das questões de caracterização, ilustrada na Figura 2, os alunos tiveram de selecionar opções representadas por conceitos apresentados a eles no Ensino Fundamental. Os conceitos foram subdivididos em categorias referentes aos assuntos de biologia, tais como citologia, fisiologia, genética, ecologia, entre outros. Foram aplicados 11 conceitos no total, representados por palavras. Dentre aqueles conceitos que os alunos se recordam de ter aprendido no Ensino Fundamental, observamos que os conceitos de célula (97\%), corpo humano (94\%), cadeia alimentar (92\%), reprodução/seres vivos (90\%) e átomo (87\%) foram os mais citados.

Os conceitos de DNA (69\%) e genética (56\%) foram apresentados a uma parcela considerável dos alunos, porém não de forma significativa. Embora não sejam explorados de forma relevante no Ensino Fundamental, os últimos são de grande importância para o entendimento da divisão celular. Os três conceitos de clonagem (34\%), transgênico (32\%) e células tronco (27\%) foram os que tiveram menor porcentagem de seleção, podendo-se concluir que não foram apresentados de forma eficiente para os alunos. Os três últimos conceitos (seres vivos, DNA e átomos) são geralmente apresentados aos alunos através da mídia (televisão, jornais e revistas). 
Figura 2. Representação gráfica percentual das respostas obtidas para a questão referente aos conteúdos apresentados no Ensino Fundamental.

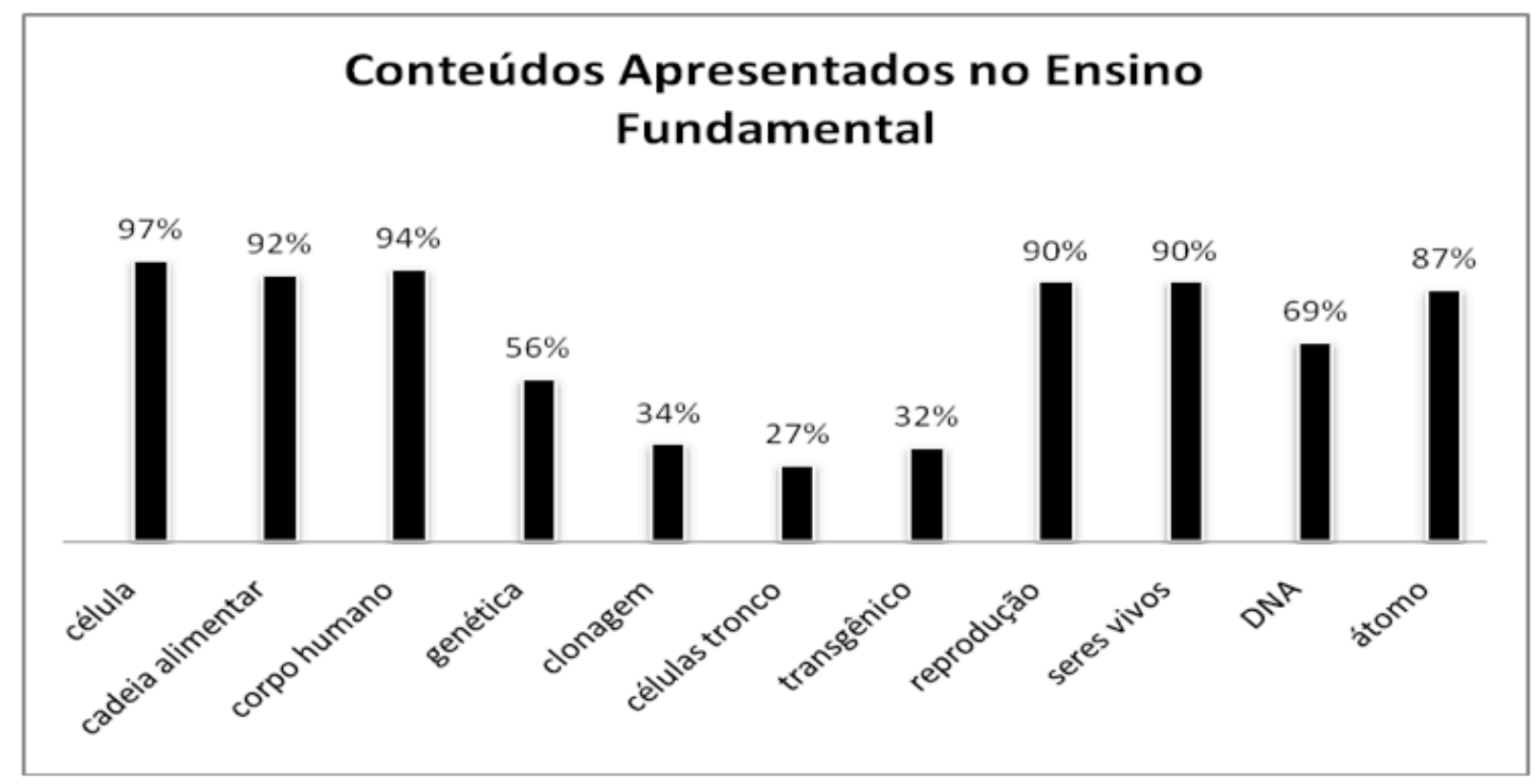

Fonte: Dados da pesquisa.

Com relação as matérias pelas quais os alunos mais se identificavam, verificamos em destaque Matemática, Física e Química, ou seja, as matérias voltadas para ciências exatas. Desta forma, foi constatado que matéria de Biologia (34\%) não é a das mais apreciadas pelos alunos dos cursos técnicos integrado ao ensino médio do Ifes, campus Vitória.

Questionário sobre concepções prévias dos alunos

Durante a aplicação dos questionários, foi possível observar algumas ideias predominantes entre os alunos investigados e alguns comportamentos que podem servir de elementos para a análise dos dados. Duas condutas foram mais evidentes: entrementes a formulação das respostas, os alunos demonstraram um grande anseio em confrontar as respostas entre si e; por mais que fosse explicado que nas tarefas propostas não existiam respostas certas ou erradas e o objetivo era saber o que cada aluno conhecia sobre determinada situação, eles insistiam em perguntar se as respostas estavam "certas" ou "erradas". 
Tomando como base a questão "0 que você entende por divisão celular?”, os dados foram categorizados e subdivididos em categorias inferiores que buscam facilitar a compreensão dos resultados, conforme a Quadro 2 .

Quadro 2. Categorias gerais e subcategorias, respostas e quantidade/porcentagem de alunos referentes aos resultados obtidos sobre a questão discursiva referente ao conhecimento prévio dos alunos sobre divisão celular.

\begin{tabular}{|c|c|c|c|}
\hline CATEGORIA & SUBCATEGORIA & RESPOSTAS & $\begin{array}{l}\text { QUANTIDADE/ } \\
\text { PORCENTAGEM }\end{array}$ \\
\hline \multirow{2}{*}{$\begin{array}{l}\text { Conceituação } \\
\text { Correta (CC) }\end{array}$} & $\begin{array}{l}\text { Relaciona os } \\
\text { tipos e suas } \\
\text { funções }\end{array}$ & $\begin{array}{l}\text { - "É a divisão da célula. Pode ser pela meiose (ocorre na formação dos gametas), ou pela } \\
\text { mitose (geração de células para o corpo a partir de células-tronco)". } \\
\text { - "Existem dois tipos: Mitose: meio utilizado pelo organismo para crescer e regenerar. Meiose: } \\
\text { meio utilizado na produção de gametas". }\end{array}$ & $10 / 7 \%$ \\
\hline & $\begin{array}{l}\text { Relaciona às } \\
\text { funções, } \\
\text { somente. }\end{array}$ & $\begin{array}{l}\text { - "É uma multiplicação das células com o intuito de renovação tecidual e crescimento, sendo } \\
\text { importante também na produção de gametas". } \\
\text { - "É uma forma de o corpo renovar seus tecidos e também de criar gametas para reprodução" }\end{array}$ & $6 / 4 \%$ \\
\hline $\begin{array}{l}\text { Conceituação } \\
\text { Generalizante } \\
\text { (CG) }\end{array}$ & $\begin{array}{l}\text { Vagos em termos } \\
\text { conceituais }\end{array}$ & $\begin{array}{l}\text { - "É o processo em que a célula se divide para formar novas" } \\
\text { - "Divisão da célula para produção de novas" }\end{array}$ & 27 / 19\% \\
\hline \multirow{6}{*}{$\begin{array}{l}\text { Conceituação } \\
\text { Parcialmente } \\
\text { Correta (CPC) }\end{array}$} & $\begin{array}{l}\text { Especifica os } \\
\text { Tipos }\end{array}$ & $\begin{array}{l}\text { - "Divisão da célula por meiose ou mitose". } \\
\text { - "É feita por meio da mitose e meiose" }\end{array}$ & 21 / 15\% \\
\hline & $\begin{array}{l}\text { Conceito focado } \\
\text { em ploidia }\end{array}$ & $\begin{array}{l}\text { - "Divisão celular é o processo em que a célula-mãe pode formar } 2 \text { células } 2 \text { n ou } 4 \text { células com } \\
\text { n." } \\
\text { - "É um meio de multiplicação celular que origina células haploides e diploides" }\end{array}$ & $5 / 4 \%$ \\
\hline & $\begin{array}{l}\text { Noção vaga de } \\
\text { Mitose }\end{array}$ & $\begin{array}{l}\text { - "É a capacidade que uma célula tem de se multiplicar, formando um corpo, com trilhões de } \\
\text { células". } \\
\text {-"É o processo de desenvolvimento da estrutura de um ser" }\end{array}$ & $8 / 6 \%$ \\
\hline & $\begin{array}{l}\text { Faz referência às } \\
\text { Fases }\end{array}$ & $\begin{array}{l}\text {-"Uma série de fases divididas por acontecimentos que dividem a célula em duas em cadeia } \\
\text { sendo que as células filhas podem ou não serem iguais à célula mãe" } \\
\text {-"Mitose, meiose, e suas respectivas fases". }\end{array}$ & $2 / 1 \%$ \\
\hline & $\begin{array}{l}\text { Explicação } \\
\text { através de } \\
\text { desenhos }\end{array}$ & Em anexo. & $4 / 3 \%$ \\
\hline & $\begin{array}{l}\text { Relaciona à } \\
\text { reprodução }\end{array}$ & $\begin{array}{l}\text {-"Reprodução assexuada" } \\
\text {-"Reprodução assexuada, onde as células filhas tem as mesmas características da célula-mãe." } \\
\text {-"O modo de reprodução das células" }\end{array}$ & $4 / 3 \%$ \\
\hline \multirow{5}{*}{$\begin{array}{l}\text { Conceituação } \\
\text { Incorreta (CI) }\end{array}$} & $\begin{array}{l}\text { Conceituação } \\
\text { Completamente } \\
\text { Incorreta }\end{array}$ & $\begin{array}{l}\text {-"Quando a célula se divide em duas células menores" } \\
\text {-"Processo pelo qual os organismos dependendo da sua quantidade de células, ou crescem ou } \\
\text { se multiplicam" } \\
\text {-"Uma forma de reprodução dos seres assexuados." } \\
\text { _"Células se dividindo pela metade" }\end{array}$ & 15 / 11\% \\
\hline & Conceito trocado & $\begin{array}{l}\text {-"São dois tipos: mitose e meiose (somente em gametas). Mitose: é o processo pelo qual a } \\
\text { célula dá origem a quatro novas células } 2 \text { n (cada uma com } 46 \text { cromossomos). Meiose: } \\
\text { processo pelo qual a célula dá origem a duas novas células n ( } 23 \text { cromossomos cada)" }\end{array}$ & $1 / 1 \%$ \\
\hline & $\begin{array}{l}\text { Relação } \\
\text { Incorreta com } \\
\text { Intérfase }\end{array}$ & $\begin{array}{l}\text {-"É quando a célula aumenta o tamanho dobro ou aumenta o material genético e se divide } \\
\text { formando assim duas células semelhantes a original" } \\
\text {-"Divisão celular é o processo de duplicação do DNA e "divisão" da célula, gerando uma nova } \\
\text { célula idêntica." }\end{array}$ & $4 / 3 \%$ \\
\hline & $\begin{array}{l}\text { Relação } \\
\text { Incorreta com } \\
\text { Citologia }\end{array}$ & $\begin{array}{l}\text {-"Estudo das organelas que compõem a célula." } \\
\text {-"Divisão da célula quanto funções das partes das células." }\end{array}$ & $8 / 6 \%$ \\
\hline & $\begin{array}{l}\text { Referencia } \\
\text { bipartição }\end{array}$ & $\begin{array}{l}\text {-"Pelo o que eu me lembro: é como se fosse a reprodução das células da maneira assexuada } \\
\text { por bipartição com umas } 5 \text { etapas, eu acho." } \\
\text {-"Mitose e meiose, bipartição." }\end{array}$ & $3 / 2 \%$ \\
\hline
\end{tabular}


A partir de respostas semelhantes às apresentadas acima, foi possível observar vários aspectos sobre o conhecimento que os alunos apresentavam sobre o assunto de Divisão Celular no momento da aplicação do questionário. A maior parte deles (19\%) apresentou uma resposta generalizante, na qual houve somente uma básica interpretação do que foi perguntado. Em algumas respostas, observamos uma maior preocupação em somente citar os tipos da divisão celular (15\%). Esses resultados, que somados geram a maioria, nos mostram que o assunto foi fracamente abordado durante o Ensino Fundamental.

Em seguida, foi obtido um alto percentual de conceituações completamente incorretas (11\%), o que denota um conhecimento equivocado por conta de os alunos não terem visto o assunto de divisão celular profundamente. Fatores como a dispersão da atenção dos alunos durante a aplicação do questionário podem ter contribuído para isso, como no exemplo de conceito trocado da Tabela 2. Uma grande parcela de alunos que responderam incorretamente mostrou uma preocupação em citar o que já estava representado pelo enunciado da questão, como pode-se observar em um exemplo da Tabela 2: "Células se dividindo pela metade". Havia também as respostas que eram incorretas por conta de os alunos relacionarem a outros assuntos que não a divisão celular. Esses assuntos podem estar diretamente ligados a aqueles mais citados na Figura 2, como "células", "seres vivos" e "corpo humano". Tais conteúdos poderiam ter sido mais focalizados ao longo das séries anteriores e por isso, confundido no momento de relacionar a outros mais recentes, como a divisão celular.

As respostas corretas e completas totalizaram 7\%. É importante ressaltar que alguns alunos já tiveram um contato mais aprofundado com o assunto, por poderem ter cursado pelo menos um ano do Ensino Médio. Isso pode ter colaborado com o resultado. As mesmas tiveram uma boa interpretação por parte dos alunos, tanto dos conceitos quanto pela citação de funções dos processos de meiose e mitose. As parcialmente corretas tiveram relação principalmente com a mitose e com as fases e tipos de modo geral, demonstrando um conhecimento limitado somente a expressões, mas sem especificação de seus conceitos.

Assim, pode-se concluir que uma pequena parcela de alunos que cursaram o primeiro ano do Ensino Médio em outra instituição ou que tiveram contato com o conteúdo na mesma semana de aplicação do questionário, tiveram uma aprendizagem significativa dos conceitos de mitose 
e meiose. Entretanto, para a grande maioria dos alunos observamos uma percepção generalizante dos conceitos, se limitando muitas vezes a reproduzir o significado das palavras "Divisão celular", que obviamente, representa a divisão da célula.

Dessa forma, fica claro que o conhecimento sobre o assunto divisão celular é bastante restrito ao ambiente formal de ensino, onde os meios de comunicação, como televisão, revistas, internet, jornal entre outros, pouco influenciam nas concepções prévias sobre o tema. Uma vez que a aprendizagem escolar é influenciada pelo que o aluno já sabe, o presente estudo demonstra que as concepções prévias sobre divisão celular que o aluno trás do ensino fundamental não apresentam obstáculos para a apropriação do conhecimento cientificamente aceito. Entretanto, o professor de biologia deve estar ciente que o aluno com deficiência de conteúdos no ensino fundamental, muitas vezes não apresenta capacidade cognitiva para aprender a partir de seus conhecimento prévios, visto que esse se limita a conceitos generalizantes.

\section{CONSIDERAÇÕES FINAIS}

Compreende-se que é necessário um planejamento do ensino, partindo do princípio que os alunos já sabem algo, e em seguida inserir novos conceitos, fornecendo assim situações que possam ampliar suas concepções acerca de um determinado assunto, propiciando-lhes argumentos para que possam refletir sobre os fenômenos que o cercam, tornando-os formadores de senso crítico.

As concepções alternativas dos alunos, se estas forem compartilhadas com os professores e aceitas por eles, poderão ser utilizadas como ponto de partida para a abordagem de um novo conceito em sala de aula. Neste sentido, os alunos se sentirão como partes constituintes e ativas do processo de construção do conhecimento, prevalecendo o trabalho coletivo em sala de aula.

O presente trabalho mostrou que o conhecimento sobre o assunto divisão celular é bastante restrito ao ambiente formal de ensino e que os alunos possuem apenas uma visão limitada e generalizante do tema. Em vista do que foi exposto, sugerimos que o ensino dos conceitos de 
divisão celular seja precedido de um momento de problematização que apresente aos alunos fatos e situações encontradas no cotidiano e na mídia que estejam vinculadas ao tema, tais como câncer, células tronco, regeneração, reprodução entre outros para seja possível resgatar conhecimentos prévios a fim de possibilitar uma aprendizagem significativa.

\section{AGRADECIMENTOS}

Deixamos expressos nossos sinceros agradecimentos às seguintes instituições e pessoas, sem as quais o presente trabalho teria sido impossível: à FAPES e FACITEC pela receptividade, acolhida e apoio técnico e administrativo com nosso trabalho, e por serem responsáveis por nossas bolsas de ensino; ao IFES e a FAPES através do PIC-Jr \#55121551/2011 pelo financiamento de nosso projeto, sem o qual não seriam viáveis nossas pesquisas e discussões.

\section{REFERÊNCIAS}

ALVES-MAZZOTTI, A. J. GEWANDSZNAJDER, F. 0 método nas ciências naturais e sociais: pesquisa quantitativa e qualitativa. São Paulo: Pioneira, 1999. 203p

ARDOINO, J. Nota a Propósito das Relações entre a Abordagem Multirreferencial e a Análise Institucional. In J.G. Barbosa (org). Multirreferencialidade nas Ciências e na Educação. São Carlos: UFSCar, 1998. p.24-41.

AUSUBEL, D. P. A aprendizagem significativa: a teoria de David Ausubel. São Paulo: Moraes, 1982.

BASTOS, F. 0 conceito de célula viva entre os estudantes de segundo grau. São Paulo, 1991. Dissertação (Mestrado em Educação) - Faculdade de Educação, Universidade de São Paulo.

BOGDAN, R.; BIKLEN, S. Investigação Qualitativa em Educação. Porto: Porto Editora, 1991. $336 \mathrm{p}$.

CHALMERS, A. F. A depêndencia que a observação tem da teoria. In: . O que é ciência afinal? São Paulo: Brasiliense, 1993.

DRIVER, R. Un enfoque constructivista para el desarrolho del currículo en ciencias. Enseñanza de Las Ciencias, 6(2): 109 -120, 1988. 
FLORENTINO, A. Fundamentos da educação 1. v.1, Rio de Janeiro: Fundação Cecierj, 2004. 153p.

FRACALANZA, H. \& NETO J. M. O livro didático de ciências: Problemas e soluções. Ciência \& educação. São Paulo, 2003. n. 2 p. 147-157.

LOPES, Fernanda Muniz Brayner; ALMEIDA, Ageu; LEÃO, Ana Maria dos Anjos Carneiro; JÓFILI, Zélia Maria Soares. Obstáculos à apropriação dos conceitos de ciclo celular por alunos do ensino médio. V ENPEC, Bauru, Brasil (Congresso). In: V Encontro Nacional dos Pesquisadores em Educação e Ciências, 2005, Bauru. Anais do V ENPEC, 2005.

LUNETTA, V. N. Actividades práticas no ensino da Ciência. Revista Portuguesa de Educação, v. 2, n. 1, p. 81-90, 1991.

POLETTI, André. 0 professor e a gestão do conhecimento. Profissão mestre, São Paulo, p. 22-23, set. 2002.

SÁ, Risonilta Germano Bezerra de; CARNEIRO-LEÂO, Ana Maria dos Anjos; JóFILI, Zélia. Concepções espontâneas de respiração pulmonar por alunos do ensino fundamental I. V ENPEC, Bauru, Brasil (Congresso). In: V Encontro Nacional de Pesquisadores em Educação em Ciências, 2005, Campinas. Anais do V ENPEC, 2005.

SIMPSON, M.; ARNOLD, B. The inappropriate use of sub-sumer in biology learning. European Journal of Science Education, v. 4, n. 2, p. 173-178, 1982. 